\title{
MEMBANDINGKAN JUMLAH LEUKOSIT DAN NILAI LAJU ENDAP DARAH PASIEN TUBERKULOSIS PARU SEBELUM DAN SETELAH PENGOBATAN
}

\author{
Chairani $^{1 *}$, Eka Novita ${ }^{1}$ \\ ${ }^{1}$ Sekolah Tinggi Ilmu Kesehatan Perintis Padang \\ Jalan Adinegoro KM 17 Simpang Kalumpang Padang \\ *Email: rani_arizal@yahoo.co.id
}

\begin{abstract}
Tuberculosis is a serious health problem that should be concerned. According statistic of The World Health Organization (WHO) show there are 1,7 million deaths due to tuberculosis. Indonesia inclue one of 3 highest incidence of tuberculosis cases in the world. This study aimed to determine the number of leucocytes and erithrocyte sediment rate (ESR) with pulmonary tuberculosis before and after administration of the anti-tuberculosis drugs (OAT). This study used description crosssectional research design. Observations were carried out in patients with tuberculosis who received therapy for 6 months OAT agains leucocytes and ESR before and after treatment. Subjects were new case of pulmonary tuberculosis with acid fast bacilli (BTA) positive and BTA negative Rontgen positive in Dharmasraya district. Materials such examination whole blood samples with EDTA anticoagulant. The result subject are 30 people. Examination of leucocytes and ESR performed before and after administration of the OAT. Result of data analysis showed that changesin the number of leucocytes significance value $p=0,000(<0,05)$ and ESR significance value $\mathrm{p}=0,000(<0,05)$. This suggest that there are significant differences in the number of the leucocytes and ESR before and after administration of the antituberculosis drugs.
\end{abstract}

Keywords: Pulmonary tuberculosis, Leucocytes, Erithrocyte Sediment Rate, Antituberculosis drugs.

\section{PENDAHULUAN}

Tuberkulosis (TBC) adalah penyakit menular yang menjadi perhatian dunia. Angka kesakitan dan kematian akibat TBC pun masih tinggi. Berdasarkan data WHO tahun 2009. 1,7 juta orang di dunia meninggal karena $\mathrm{TBC}$, hal ini dikarenakan penderita tidak sembuh terutama penderita menular TBC BTA positif. Di Indonesia, setelah Infeksi Saluran Pernafasan Akut (ISPA), TBC termasuk urutan teratas penyebab utama kematian dan kesakitan. Tahun 2014 jumlah penderita TBC di Indonesia mencapai 183 orang/100.000 penduduk. Indonesia menduduki urutan ketiga setelah India dan China dalam jumlah penderita TBC di dunia.
Diagnosis penyakit tuberculosis dapat dilakukan dengan menemukan kuman Mycobacterium tuberculosis yang terdapat dalam sputum atau jaringan paru secara biakan, akan tetapi pemeriksaan laboratorium lain juga membantu dalam memperkuat diagnosis, yaitu pemeriksaan darah diantaranya adalah pemeriksaan jumlah leukosit dan nilai Laju Endap Darah (LED). Peningkatan jumlah leukosit dan LED dapat menunjukkan proses tuberkulosis yang sedang aktif. Ini biasanya ditemukan pada penderita baru TBC, yaitu penderita TBC diawal penularan ataupun penderita TBC yang belum diobati (Bestari \& Adang, 2014).

Peningkatan jumlah leukosit diawal penularan ini berkaitan dengan fungsinya sebagai pertahanan tubuh. Begitu tubuh 
mendeteksi adanya infeksi maka tubuh akan memproduksi leukosit lebih banyak untuk melawan infeksi. Peningkatan LED terjadi karena pada penderita tuberculosis paru terjadi proses hipergammaglobulinemia, dimana terjadi respon dari sistim imun yang dirangsang oleh berbagai stimulasi, peningkatan globin di dalam darah penderita tuberculosis paru akan menyebabkan agregasi dari sel-sel darah merah (eritrosit) yang menyebabkan peningkatan LED. Setelah penderita TBC meminum OAT (Obat Anti Tuberkulosis) selama 6 bulan dan proses tuberculosis tidak lagi aktif maka jumlah leukosit dan nilai LED akan kembali normal (Bestari \& Adang, 2014).

Berdasarkan latar belakang di atas maka penulis ingin melakukan penelitian tentang "Membandingkan Jumlah Leukosit dan Nilai Laju Endap Darah Pasien Tuberkulosis Paru Sebelum dan Setelah Pengobatan". Tujuan penelitian ini adalah untuk mengetahui perbedaan jumlah leukosit dan laju endap darah pasien tuberculosis paru sebelum dan setelah pengobatan dalam jangka waktu 6 bulan dengan Obat Anti Tuberkulosis.

\section{METODE PENELITIAN}

Penelitian dilakukan secara deskriptif dengan desain cross sectional. Penelitian dilakukan pada bulan Oktober s/d Desember 2016 di Laboratorium Kesehatan Daerah Kab. Dharmasraya. Populasi adalah semua pasien TBC Paru BTA positif dan BTA negative rontgen positif di Kabupaten Dharmasraya sebelum pengobatan dan yang telah meminum OAT selama 6 bulan. Sampel diambil 30 orang dari semua pasien TBC Paru yang belum mendapat pengobatan dan setelah pengobatan dengan OAT secara purposive sampling. Data Primer diperoleh dengan memeriksa jumlah leukosit dan nilai Laju Endap Darah pasien TBC Paru yang telah selesai pengobatan.

Data Sekunder dikumpulkan dengan pencatatan data pasien yang TBC Paru sebelum minum Obat Anti Tuberkulosis dari pengelola program TB Puskesmas dan dokter spesialis paru RSUD Sungai Dareh. Instrumen penelitian adalah hematology analyzer dan alat pemeriksa LED metode Westergren. Adapun langkahlangkah pengolahan data dapat dilakukan dengan: Editing yaitu pemeriksaan kelengkapan dan kejelasannya. Coding yaitu memberikan variabel disetiap data variabel untuk memudahkan dalam pengolahan selanjutnya Entry yaitu mamasukkan data ke dalam program SPSS sebelum diolah. Cleaning yaitu pemeriksaan data yang dientrykan agar data bersih dari kesalahan sehingga kode dapat terbaca.

\section{HASIL PENELITIAN}

Pada penelitian ini didapatkan rentang umur kelompok laki-laki adalah antara 19 sampai 85 tahun. Sedangkan rentang umur pada kelompok perempuan adalah 25 sampai 69 tahun. Kelompok umur terbanyak penderita $\mathrm{Tb}$ paru adalah kelompok umur $\leq 41$ tahun. Dari hasil penelitian, jumlah sampel laki-laki lebih banyak dibanding perempuan $[n=30,60 \%$ ] yang diuji berdasarkan karakteristik jenis kelamin. Hasil ini sejalan dengan penelitian (Puspitasari, Wongkar, \& Surachmanto, 2014) tentang "Profil Pasien Tuberkulosis Paru di Poliklinik Paru RSUP Prof. Dr. R. D. Kandou Manado" yang menunjukkan subjek penelitian laki-laki lebih dominan [n=52, 76,9\%].

Penelitian ini juga menunjukkan penderita TB terbanyak berusia 19-50 tahun (63,3\%). Disamping itu penelitian (Mulyadi, Suangkupon, \& Dermawan, 2011) tentang "Profil Penderita Tuberkulosis Paru di Pesisir Pantai Aceh Barat Daya" menunjukkan TB terbanyak berusia $15-54$ tahun $(75,68 \%)$. Data menunjukan dewasa muda dengan usia produktif sebagian besar penderita TB.

\section{Hasil Uji Statistik Pemeriksaan Jumlah Lekosit}

Bagian 1. Paired Sample Statistik

Menunjukkan rata rata pemeriksaan sebelum dan sesudah pengobatan

- Sebelum pengobatan rata rata jumlah lekosit adalah $12.816 / \mathrm{mm} 3$.

- Sesudah pengobatan rata rata jumlah lekosit adalah $7.080 / \mathrm{mm} 3$. 


\section{Bagian 2. Paired Sample Correlation}

Hasil menunjukkan korelasi 2 variabel 0.614 dengan sig. sebesar 0.000 dengan pemeriksaan sebelum dan sesudah adalah kuat dan signifikan.

Bagian 3. Hasil uji hipotesis

$\mathrm{H}_{0}$ : Jumlah lekosit sebelum pengobatan dan sesudah pengobatan tidak ada perbedaan

$\mathrm{H}_{\mathrm{a}}$ : Jumlah lekosit sebelum dan sesudah pengobatan ada perbedaan $\alpha: 95 \%$

Nilai t hitung sebesar 22,847 dengan sig ( 2 tailed) 0.000 . sig $<0,05$ dan $t$ hitung $>\mathrm{t}$ tabel $(1,699)$, maka $\mathrm{H}_{\mathrm{a}}$ diterima, $\mathrm{H}_{0}$ ditolak. Hasil ini menunjukkan jumlah leokosit mengalami perbedaan setelah dilakukan pemeriksaan sebelum pengobatan serta setelah pengobatan dengan OAT.

Hasil ini sesuai dengan yang dilakukan (Bestari \& Adang, 2014) tentang "Perbedaan Kadar Leukosit Sebelum dan Sesudah Pemberian Obat Antituberkulosis Pada Fase Awal" yang menunjukkan terjadi penurunan jumlah leukosist yang signifikan setelah pengobatan dengan OAT.

\section{Hasil Uji Statistik Pemeriksaan Nilai LED}

Bagian 1. Paired Sample Statistik

Menunjukkan rata rata pemeriksaan sebelum dan sesudah pengobatan

- Sebelum pengobatan rata rata nilai LED adalah 91,1/jam

- Sesudah pengobatan rata rata nilai LED adalah 11,4/jam

Bagian 2. Paired Sample Correlation

Korelasi dua variabel yaitu 0.367 dengan sig. sebesar 0.046 yang menunjukkan pemerikasaan sebelum dan sesudah kuat dan signifikan.

Bagian 3. Hasil Uji Hipotesis

Hipotesis yang diajukan :

$\mathrm{H}_{0}$ : Nilai LED sebelum pengobatan dan sesudah pengobatan tidak ada perbedaan

Ha : Nilai LED sebelum dan sesudah pengobatan memiliki perbedaan

$\alpha: 95 \%$.

$\mathrm{t}$ hitung $=19,286$ dengan sig ( 2 tailed $)$ 0.000. hal ini karena sig $<0,05$ dan $\mathrm{t}$ hitung $>\mathrm{t}$ tabel (1,699), maka $\mathrm{H}_{\mathrm{a}}$ diterima, $\mathrm{H}_{0}$ ditolak. Nilai LED mengalami perbedaan antara sebelum dan sesudah pengobatan dengan OAT. Sesuai dengan hasil penelitian (Novita, 2011) tentang "Membandingkan Nilai Laju Endap Darah Pasien Tuberkulosis Paru Sebelum dan Sesudah Pengobatan Dengan Obat Anti Tuberkulosis" yang mendapatkan hasil bahwa terdapat perbedaan yang bermakna antara nilai LED sebelum dan sesudah pengobatan dengan OAT.

\section{KESIMPULAN}

1. Jumlah leokosit sebelum pengobatan dan sesudah pengobatan dengan OAT mengalami perbedaan $(12,816 / \mathrm{mm} 3-$ 7,080/mm3)

2. Nilai LED sebelum dan sesudah pengobatan dengan OAT memiliki nilai yang berbeda (91,1/jam - 11/jam).

\section{DAFTAR KEPUSTAKAAN}

Bestari, G., \& Adang. (2014). Perbedaan Kadar Leukosit Sebelum dan Sesudah Pemberian Obat Anti Tuberkulosis Pada Fase Awal,. In Yogyakarta: Fakultas Kedokteran dan Ilmu Kesehatan Universitas Muhammadyah.

Mulyadi, Suangkupon, R., \& Dermawan, I. (2011). Profil penderita tuberkulosis paru di pesisir pantai Aceh Barat Daya (Kajian di Puskesmas Biangpidie). Jurnal Respirologi Indonesia, 31(2).

Novita, E. (2011). Membandingkan Nilai Laju Endap Darah Pasien TBC Paru Sebelum dan Setelah Pengobatan Dengan Obat Anti Tuberkulosis Paru. Padang: Stikes Perintis.

Puspitasari, P., Wongkar, M., \& Surachmanto, E. (2014). Profil Pasien Tuberjulosis Paru di Poliklinik Paru RSUP Prof. Dr. R.D. Kandou Manado. Jurnal E-Clinic, 2(1). 